\title{
Perceptions of Residents of the Kinkole Neighborhood on the Role of Trees in the Peri-urban Environment of Kinshasa, Democratic Republic of Congo
}

\author{
Jean Semeki Ngabinzeke ${ }^{1,}$, , Heritier Kaki Mokuba ${ }^{1}$, Jean-Paul Tasi Mbuangi, \\ Prince Baraka Lucungu ${ }^{1}$, Papy-Claude Bolaluembe Boliale ${ }^{1}$, Jean-Marie Kahindo Muhongya ${ }^{2}$ \\ ${ }^{1}$ Department of Natural Resource Management, Faculty of Agricultural Sciences, University of Kinshasa, Kinshasa, Democratic Republic of \\ the Congo \\ ${ }^{2}$ Department of Botany, Faculty of Science, University of Kisangani, Kisangani, Democratic Republic of the Congo
}

\section{Email address:}

jean.semeki@unikin.ac.cd(J. S. Ngabinzeke)

*Corresponding author

\section{To cite this article:}

Jean Semeki Ngabinzeke, Heritier Kaki Mokuba, Jean-Paul Tasi Mbuangi, Prince Baraka Lucungu, Papy-Claude Bolaluembe Boliale, JeanMarie Kahindo Muhongya. Perceptions of Residents of the Kinkole Neighborhood on the Role of Trees in the Peri-urban Environment of Kinshasa, Democratic Republic of Congo. Journal of Plant Sciences. Vol. 9, No. 2, 2021, pp. 46-53. doi: 10.11648/j.jps.20210902.13

Received: March 26, 2021; Accepted: April 20, 2021; Published: April 29, 2021

\begin{abstract}
The city of Kinshasa, capital of the Democratic Republic of Congo, is currently experiencing unprecedented urban and peri-urban development, which is reflected in the degradation and loss of vegetation cover. There is a real need to conduct sociological studies on trees to help leaders in their decision-making. This research aims to analyze the perception of the population on the role of trees in the peri-urban area of the city of Kinshasa. The data were collected through a survey conducted in the Kinkole neighborhood, located in the eastern part of the city. A total of 321 residential plots were sampled between September and November 2017 to conduct semi-structured individual interviews. After compilation, the collected information was synchronized and then analyzed using Excel software to produce relative and absolute frequencies. The results obtained show that trees are primarily planted for economic, food, shade, and pharmacopoeia needs. The trees planted in the plots are mostly fruit trees, of which three species alone account for more than two-thirds of the planting. These are the mango tree (Mangifera indica) with $31.3 \%$ of trees planted, followed by the avocado tree (Persea americana) representing 31.1\% of the plantation and then the safflower tree (Dacryodes edulis) representing $25.7 \%$. The seedlings of these trees come mainly from consumed seeds. However, nearly half of the residents feel that they do not need to add other trees to their plots due to lack of space or property rights. These results reveal the urgency of promoting urban and peri-urban forestry through the development of a policy and strategies for the adequate management of peri-urban spaces in the city of Kinshasa. This is in order to improve the quality of life of the human population in order to face the current challenges related to the effects of climate change in urban and peri-urban areas.
\end{abstract}

Keywords: Uncontrolled Urbanization, Space Planning, Parcel Trees, Planting, Urban and Peri-urban Forestry, Kinshasa

\section{Introduction}

It is estimated that by 2050 , humanity will experience an urban development of nearly $70 \%$ of all urban areas, with a sprawl of more than $90 \%$ in the cities of Asia and Africa [4]. For example, in 2010, Africa recorded more than a quarter of the 100 most dynamic cities in the world in terms of demography, 52 of which had at least one million inhabitants [2]. However, the acceleration of urbanization in developing countries is particularly characterized by the transformation of a rural society into an urban society, commonly known as "uncontrolled urbanization" [15, 23]. This disproportionate evolution between the growth of the population and the urbanized surface is at the origin of 
considerable ecological consequences, the most noticeable of which are the disappearance of emblematic green spaces in cities $[8,34]$. This leads to spatial changes, characterized in particular by a new hierarchy of land use and natural resources $[1,20]$.

This problem is particularly worrying in the city of Kinshasa, which has experienced both strong demographic and urban growth since the country's independence in 1960. Indeed, the population of this megalopolis has increased from 400,000 inhabitants in 1960 to $7,500,000$ in 2005, with a density that has increased, during the same period, from about $60 \mathrm{hab} /$ ha to $170 \mathrm{hab} / \mathrm{ha}$ [13]. In 2016, Kinshasa reached nearly $12,071,463$ inhabitants, an increase of $61.6 \%$ compared to its population in 1960 (PopulationData.net). This demographic growth then translates into a rapid and anarchic spatial transformation of the urban space on the peri-urban spaces, formerly occupied by a vegetation cover $[12,15]$. The built-up area of the city of Kinshasa increased from 6,800 ha in 1960 to 43,000 ha in 2005 [13]. The city is expanding and becoming denser in its entirety and especially in the peri-urban areas to the detriment of rural wooded areas [16]. There is strong pressure on these areas for new residential developments. In addition, due to the precarious living conditions that prevail in these environments, residents exert increased pressure on natural resources; trees are frequently cut down to produce wood energy, construction and other services for domestic and commercial purposes, the corollary of which is the degradation of the space [3].

This socio-demographic and landscape dynamic, as well as the desire to ensure more ecologically sustainable cities, has led to the emergence of urban and peri-urban forestry. It aims at the development, cultivation and management of trees in order to ensure their contribution to the physiological, social, economic and environmental well-being of urban society and its periphery $[7,25]$. The concept has emerged since the end of the 19th century in developed countries (Larouche, 2016), while in developing countries, studies on this topic are only at their embryonic stage $[14,30]$. In the DRC, the topics addressed have determined the contribution of fruit trees to food security [18], assessed tree biomass [11], analyzed spatial dynamics [13, 27, 32], characterized tree vegetation and green spaces $[26,28]$. However, very few studies have focused on people's perceptions of urban and peri-urban forestry. Ncutirakiza and Kadiata [19] assessed the role of trees in the urban environment in five communes of Kinshasa, concluding that the environmental usefulness of trees was not well known by the city dwellers surveyed. Poloringi et al [23] also point out that sociological surveys can reveal people's opinions on the benefits of trees in urban and peri-urban areas in order to guide urban development policies and programs.

This case study is part of the preliminary studies required to develop a strategy and action plan for the implementation of urban and peri-urban forestry in the provincial city of Kinshasa, capital of the Democratic Republic of Congo (DRC). The research was initiated in order to trace the profile of the residents, to draw up an inventory of the activity of plot tree planting and the inherent constraints, as well as to describe the role recognized to the tree by the residents in the Kinkole neighborhood in the Kinshasa town.

This socio-demographic and landscape dynamic, as well as the desire to ensure more ecologically sustainable cities, has led to the emergence of urban and peri-urban forestry [24]. It aims at the development, cultivation and management of trees in order to ensure their contribution to the physiological, social, economic and environmental wellbeing of urban society and its periphery [7, 25]. The concept has emerged since the end of the 19th century in developed countries (Larouche, 2016), while in developing countries, studies on this topic are only at their embryonic stage $[14,30]$. In the DRC, the topics addressed have determined the contribution of fruit trees to food security [18], assessed tree biomass [11], analyzed spatial dynamics $[13,27,32]$, characterized tree vegetation and green spaces [26, 28]. However, very few studies have focused on people's perceptions of urban and peri-urban forestry. Ncutirakiza and Kadiata [19] assessed the role of trees in the urban environment in five communes of Kinshasa, concluding that the environmental usefulness of trees was not well known by the city dwellers surveyed. Poloringi et al [23] also point out that sociological surveys can reveal people's opinions on the benefits of trees in urban and periurban areas in order to guide urban development policies and programs.

This case study is part of the preliminary studies required to develop a strategy and action plan for the implementation of urban and peri-urban forestry in the provincial city of Kinshasa, capital of the Democratic Republic of Congo (DRC). The research was initiated in order to trace the profile of the residents, to draw up an inventory of the activity of plot tree planting and the inherent constraints, as well as to describe the role recognized to the tree by the residents of the peripheral neighborhood of Kinkole in Kinshasa.

\section{Methods}

\subsection{Study Site}

The study was carried out in the Kinkole neighborhood, located in the commune of N'Sele, to the east of the provincial city of Kinshasa between $4^{\circ} 19^{\prime} 29.29^{\prime \prime}$ South latitude and 15'30'30.36" East longitude. The agglomeration of Kinkole is composed of three districts: Mingali 1, Mingali 2 and Kinkole pécheur. The choice of Kinkole fisherman was motivated by the predominance of trees in the residences, unlike the other two neighborhoods. The climate is similar to that covering the city of Kinshasa, namely, a hot and humid tropical climate of type Aw4 according to the Köppen-Geiger classification [15]. The average annual temperature is $25^{\circ} \mathrm{C}$ and the average annual rainfall is around $1400 \mathrm{~mm}$ [16]. The soils are mainly sandy 
with some coarse elements and the vegetation is generally grassy and shrubby savannahs interspersed with steppe [5]. The vast majority of the population of Kinkole depend on food crops and wood energy production for domestic and commercial purposes.

\subsection{Data Collection, Processing and Analysis}

To conduct this study, 312 plots were selected out of a total of 1049 plots, which constitute all of the residences in the Kinkole neighborhood. The list of plots was obtained from the last office. This sample was defined using the Bernoulli distribution below, with a threshold of $10 \%$ and the assumption of equal sharing of opinions [29]. This was done taking into account financial constraints and especially the presence of trees in the residences.

$$
n=\frac{(1,96)^{2} \times \mathrm{N}}{(1,96)^{2}+\mathrm{I}^{2} \mathrm{x}(\mathrm{N}-1)}
$$

Where, n: size of the sample to be surveyed, N: size of the universe investigated, 1: width of the range expressing the margin of error.

The plots to be surveyed were selected using systematic sampling [6], with a sampling step of three. The sample size was calculated as the ratio of the total number of plots in the Kinkole neighborhood to the sample size of the plots to be surveyed.

The survey questionnaire was divided into three themes, including the respondent's profile, tree planting and the constraints associated with this activity, as well as the role recognized for the tree. Most of the questions were of the farmer type in order to facilitate data collection and processing. The survey was conducted from september to november 2017. In each plot, only one adult person was interviewed, with an option to be assisted by others with prior knowledge of the residence. The questionnaire was administered between 8:00 am and 4:00 pm. Respondents gave their free and informed consent to participate in the survey beforehand.

The collected data underwent a manual synchronization, and subsequent data entry, filtering and organization in Excel. The parameters analyzed included the socioprofessional characteristics of the respondents, tree planting and constraints, and the role of the tree as seen by the residents. Cross-tabulations were produced in order to deduce the portions of the different parameters evaluated in the form of percentages with the Excel software.

\section{Results}

\subsection{Socio-professional Characteristics of Respondents}

Table 1 describes the profile of the people who participated in the survey in the sampled residences. Overall, men are slightly more numerous (50.6\%) among the respondents than women (49.4\%).
Table 1. Profile of respondents.

\begin{tabular}{llll}
\hline Description & & Workforce & $\mathbf{\%}$ \\
\hline \multirow{3}{*}{ Gender } & Male & 158 & 50.6 \\
& Female & 154 & 49.4 \\
& Total & 312 & 100.0 \\
Age & 20 to 40 years old & 195 & 62.5 \\
& 41 to 60 years old & 94 & 30.1 \\
& 61 years and old & 23 & 7.3 \\
& Total & 312 & 100 \\
Level of & Illiterate & 43 & 13.8 \\
education & Primary & 94 & 30.1 \\
& Secondary & 155 & 49.7 \\
& University & 20 & 6.4 \\
& Total & 312 & 100 \\
& Small businesses & 145 & 46.4 \\
& Fishermen & 91 & 29.1 \\
& Civil servants & 25 & 8.0 \\
Occupation & Nurses & 2 & 0.6 \\
& Tailors & 5 & 1.6 \\
& Masons & 1 & 0.3 \\
& Unempoyed & 43 & 13.8 \\
& Total & 312 & 100 \\
\hline
\end{tabular}

The majority of the people surveyed were in the 20 to 40 old group, i.e., nearly two-thirds $(62.5 \%)$ of those interviewed; while the older people, those who know the history of their living environment, were few in number and represented less than one-tenth of the population surveyed. The middle age group is represented by a little less than $1 / 3$ of the surveyed population.

This table also shows that the vast majority of the population, at least $3 / 4$ of the population $(75.5 \%)$, lives from small businesses and fishing, which constitute the largest occupation of the population; other occupations are shared by the population in relatively small proportions (civil servants, nurses, seamstresses and masons). However, there is a category of people, slightly more than $1 / 10$, who are unemployed. This study also shows that the population is only moderately educated, with almost half (49.6\%) having attained at least secondary school level; with just under a third of the population able to read and write, having attended elementary school (30.1\%). A very small proportion has a very high level of education, and is therefore university educated $(6.4 \%)$. However, there are also populations that are uneducated $(13.7 \%)$. These results show that more than half of the respondents are able to understand the issues at stake in the study and the questionnaire.

In the same vein, it was found that more than half of the respondents, i.e. $51 \%(n=159)$, have resided for more than 20 years in the plots they occupy, while $32.3 \%$ $(n=100)$ have resided there between 10 and 20 years, against $16.7 \%(n=53)$ who have resided there since less than 10 years ago. These results show that more than half of the people we met had lived in the sectioned residences for several years, which would reflect the reliability of the data collected.

Regarding plot occupancy status, a large number (59.0\%) of those interviewed own their plots, while $39.9 \%$ are tenants, and a very small proportion (1.3\%) are house guards 
(Table 2).

Table 2. Parcel occupancy status.

\begin{tabular}{lll}
\hline Status & Workforce & \% \\
\hline Owner & 184 & 59.0 \\
Tenant & 124 & 39.7 \\
Janitor & 4 & 1.3 \\
Total & 312 & 100 \\
\hline
\end{tabular}

\subsection{Tree Planting}

\subsubsection{Number of Existing and Planted Trees}

More than $2 / 3$ or $75.9 \%$ of the respondents acknowledged having found between one and five trees present in the plots they occupy against $23.2 \%$ who declared having found no trees, and then, a small fringe $(0.9 \%)$ affirmed the existence of more than five trees at the time of occupying the residence (Table 3).

Among the respondents, $52.8 \%(\mathrm{n}=165)$ claimed to have planted trees in their plots compared to $47.2 \%(n=147)$ who are not interested in this activity. The vast majority of those who planted trees, $93.3 \%$, replanted their plots with one to five trees, while a minority (6.7\%) admitted to having planted more than five trees.

Table 3. Number of trees found during the plot occupation and those planted.

\begin{tabular}{lll}
\hline & Workforce & \% \\
\hline Number of trees present & \\
Zero & 72 & 23.2 \\
1 to 5 & 237 & 75.9 \\
More than 5 & 3 & 0.9 \\
Total & 312 & 100.0 \\
Number of trees planted by residents & \\
1 to 5 & 154 & 93.3 \\
More than 5 & 11 & 6.7 \\
Total & 165 & 100 \\
\hline
\end{tabular}

\subsubsection{Tree Species Planted and Uses}

The results of the surveys conducted made it possible to draw up a list of thirteen tree species commonly planted and used in the plots, three of which represent more than two thirds of the plantation, namely Mangifera indica (31.3\%), Persea americana (31.1\%) and Dacryodes edulis (25.7\%). In very small proportions, the interviewees mentioned the plantation of
Malus domestica, Artocarpus altilis, Citrus sinensis, Citrus lemon, Acacia auriculiformis, Moringa oleifera, Eucalyptus sp, Psiduim guajava, and Artocarpus heteropyllus (Lam.) (Table 4).

Table 4. Species used for planting in residences.

\begin{tabular}{lllll}
\hline $\mathbf{N}^{\circ}$ & Common name & Scientific name & Workforce & \% \\
\hline 1 & Mango tree & Mangifera indica & 158 & 31.3 \\
2 & Avocado tree & Persea americana & 157 & 31.1 \\
3 & Safflower & Dacryodes edulis & 130 & 25.7 \\
4 & Red apple & Malus domestica & 13 & 2.6 \\
5 & Breadfruit tree & Artocarpus altilis & 7 & 1.4 \\
6 & Orange tree & Citrus sinensis & 7 & 1.4 \\
7 & Lemon tree & Citrus lemon & 7 & 1.4 \\
8 & Acacia & Acacia auriculiformis & 6 & 1.2 \\
9 & Moringa & Moringa oleifera & 6 & 1.2 \\
10 & Eucalyptus & Eucalyptus sp & 5 & 1.0 \\
11 & Guava tree & Psidium guajava & 5 & 1.0 \\
12 & Mandarin tree & Citrus reticula & 3 & 0.6 \\
13 & Jackfruit & Artocarpus heterophyllus & 1 & 0.2 \\
& Total & & 505 & 100 \\
\hline
\end{tabular}

For all these tree species, fruit production, food, shade, and medicine production are the main functions of trees, as recognized by the vast majority of respondents (Table 5). These roles remain of great importance, as they contribute to the economic and social survival of residents. However, the environmental roles played by trees are not well known by the respondents, who noted in very small proportions, the windbreak, the purification of the area and the reduction of noise. This indicates their poor knowledge of the role of trees in the peri-urban environment, despite the current issues related to climate change.

Table 5. Role of trees in peri-urban areas.

\begin{tabular}{lll}
\hline Role & Workforce & \% \\
\hline Fruit production & 312 & 28.2 \\
Food & 300 & 27.1 \\
Shade & 299 & 27.1 \\
Medicines & 164 & 14.8 \\
Windbreak & 16 & 1.4 \\
Air purification & 13 & 1.2 \\
Noise reduction & 1 & 0.1 \\
Total & 1105 & 100 \\
\hline
\end{tabular}

Table 6. Uses of species planted in residences.

\begin{tabular}{|c|c|c|c|c|c|}
\hline \multirow{2}{*}{ Species } & \multicolumn{5}{|c|}{ Rank of the species in relation to its use } \\
\hline & Economic & Food & Shanding & Pharmacopoeia & Wood enrgy \\
\hline Mangifera indica & $1^{\mathrm{st}}$ & $2^{\text {nd }}$ & $3^{\text {rd }}$ & $4^{\text {th }}$ & $5^{\text {th }}$ \\
\hline Percea americana & $1^{\text {st }}$ & $2^{\text {nd }}$ & $3^{\text {rd }}$ & $4^{\text {th }}$ & $5^{\text {th }}$ \\
\hline Dacryodes edulis & $1^{\text {st }}$ & $2^{\text {nd }}$ & $3^{\text {rd }}$ & 0 & $4^{\text {th }}$ \\
\hline Malus domestica & $1^{\text {st }}$ & $2^{\text {nd }}$ & $3^{\text {rd }}$ & 0 & $4^{\text {th }}$ \\
\hline Artocarpus altilis & $1^{\text {st }}$ & 0 & 0 & 0 & 0 \\
\hline Citrus sinensis & $1^{\text {st }}$ & $2^{\text {nd }}$ & $3^{\text {rd }}$ & 0 & 0 \\
\hline Citrus lemon & $1^{\mathrm{st}}$ & $2^{\text {nd }}$ & 0 & 0 & 0 \\
\hline Acacia auriculiformis & $2^{\text {nd }}$ & 0 & 0 & 0 & $1^{\text {st }}$ \\
\hline Moringa oleifera & 0 & $2^{\text {nd }}$ & 0 & $1^{\mathrm{er}}$ & 0 \\
\hline Eucalyptus sp & $3^{\text {rd }}$ & 0 & 0 & $2^{\text {nd }}$ & $1^{\text {st }}$ \\
\hline Psidium guajava & $1^{\text {st }}$ & $2^{\text {nd }}$ & & $3^{\text {rd }}$ & 0 \\
\hline Citrus reticula & $1^{\text {st }}$ & $2^{\text {nd }}$ & 0 & 0 & 0 \\
\hline Artocarpus heterophyllus & $1^{\mathrm{st}}$ & $2^{\text {nd }}$ & 0 & 0 & 0 \\
\hline
\end{tabular}


In terms of the uses or utilities of the trees planted, the majority of fruit trees are primarily used for sale to cover economic needs. Among the main species of fruit trees most in demand (Table 6), Mangifera indica, Persea americana, Dacryodes edulis, Malus domestica, Citrus sinensis, Citrus lemon, Psidium guajava and Citrus reticula were cited. These fruit trees are also used in second place to satisfy food needs. For the pharmacopoeia, the most used species is Moringa oleifera, followed by Eucalyptus sp, Psidium guajava as well as, Mangifera indica and Percea americana. Acacia auriculiformis and Eucalyptus sp occupy the first place for the production of wood energy, while Dracryodes edulis and Malus domestica, as well as Mangifera indica and Persea americana, also provide this service, but in a very small proportion.

The ranking is based on the number of times the species has been cited for such or other uses. The number 0 indicates that the species is not used for the concerned use.

\subsubsection{Origins and Modes of Acquisition of Seedlings}

The vast majority of respondents $(93.3 \%)$ stated that the trees planted in the plots were derived from the regeneration of seeds from fruit left on the ground after being consumed (Table 7). On the other hand, the respondents very rarely resorted to environmental services or to the requested structures to obtain seedlings because of their relatively high purchase cost (1 USD per seedling).

Table 7. Origin and mode of acquisition of seedlings.

\begin{tabular}{lll}
\hline & Workforce & \% \\
\hline Origin of the seedlings & & \\
Grains of fruit consumed & 154 & 93.3 \\
Private structures & 10 & 6.0 \\
Environmental services & 1 & 0.6 \\
Total & 165 & 100 \\
Mode of acquisition & & \\
Free of charge & 154 & 93.3 \\
Purchase & 11 & 6.7 \\
Total & 165 & 100 \\
\hline
\end{tabular}

This table also shows that almost no costs are incurred to obtain the seedlings used in the planting of plot trees; most of them come from grains of consumed fruits.

\subsubsection{Need for Tree Planting in Plots}

According to Table 8 below, $40.1 \%$ of respondents do not consider it important to plant or increase the number of trees in their plots due to lack of space. On the other hand, a fringe recognized the need to plant trees where, $32.1 \%$ think that one can plant between 1 and 2 trees in a plot against, $26.9 \%$ who affirm that they can wood their plots with at least 3 trees.

Table 8. Assessment of the need for plot tree planting.

\begin{tabular}{lll}
\hline Number of trees to be planted & Workforce & \% \\
\hline 1 to 2 & 100 & 32.1 \\
At least 3 & 84 & 26.9 \\
None & 128 & 41.0 \\
Total & 312 & 100 \\
\hline
\end{tabular}

\subsubsection{Constraints to Plot Tree Planting}

From these respondents, some constraints emerge that would prevent the planting of plot trees (Table 9). These include: the availability of the space needed for tree planting, as the plots are generally already well developed or the undeveloped space is reserved for future construction. Parcel ownership status was also cited as a limiting factor for parcel tree planting. Indeed, $39.8 \%$ of respondents stated that they were not able to plant trees on the parcels they occupy because they do not own the land. Finally, a last category of respondents $(19.2 \%)$ felt that the unavailability of seedlings of certain species that they prefer does not allow them to repopulate their places of residence.

Table 9. Constraints to plot tree planting.

\begin{tabular}{lll}
\hline Contraints & Workforce & \% \\
\hline Limited space in the plot & 128 & 41.0 \\
Unavailability of seedlings of preferred species & 60 & 19.2 \\
Tenant & 124 & 39.8 \\
Total & 312 & 100 \\
\hline
\end{tabular}

\section{Discussion}

This study reveals that most of the residents in the study area concerned inherited plots of land from their deceased parents; a phenomenon that is recurrent and common in the city of Kinshasa, where a significant proportion of its inhabitants are heirs to the real estate of their parents [10]. Indeed, the socio-economic situation of the DRC, where living conditions have become increasingly precarious, does not allow the vast majority of the population to buy a plot of land nowadays [4]. Faced with this situation, the inhabitants of Kinshasa inherit and occupy family plots. This situation would justify the large proportion of respondents who are owners as opposed to tenants and janitors. The status of plot occupancy and the seniority of residents are useful parameters to take into account in a sociological survey [23], as they reveal the level of perceptions that residents have on the history of the state of plot trees and their socio-economic and environmental benefits [19]. The study showed that the majority of residents own the plots they occupy and have lived there for many years. However, most of them are men, unemployed with limited access to education, and therefore forced to stay at home or engage in petty trade to ensure their survival.

Planted almost in each of the plots that were the subject of this study, plot trees mainly meet economic, food and shelter (shade) needs. In this regard, Tréfon and Kabuyaya [31] reported that individuals based in the peri-urban areas of Kinshasa live mainly on non-timber and agricultural products exploited in their homes. According to these same authors, this situation is the result of policy failures that place the inhabitants of peri-urban areas in increasingly precarious living conditions. Fruit trees, notably Mangifera indica, followed by Persea americana and Dacryodes 
edulis, are the dominant species, and are almost present not only in all the plots surveyed but also in most homes in the city of Kinshasa $[9,18,26]$. These species, which are more commonly used for plot planting, are among the main species characteristic of common trees in urban and periurban areas of the Kinshasa region [21, 22]. They offer various goods and services to the population. Their fruits are used for both food and sale, while their leaves and bark are used for pharmacopoeia. As for the shade, the tree plays the role of shelter for the residents because of the heat of the sun and the degradation of the quality of the environment. In this regard, Vergiette and Labrecque [33] indicated that in tropical regions, the combined effect of shading and evaporation becomes important at the scale of a dwelling because, the maximum temperature can be reduced by $0.7^{\circ}$ to $1.3^{\circ} \mathrm{C}$ compared to open areas without trees. As for Leyden [17], he points out that by providing shade, i.e. meeting spaces, trees in peri-urban and urban environments, participate in the improvement of the quality of social links between residents. Trees therefore promote a necessary microclimate in peri-urban and urban areas, such as those in the city of Kinshasa, which are undergoing uncontrolled urbanization. Because of their socio-economic role recognized by residents, the main tree species used for plot planting need to be popularized and included in largescale restoration and planting programs.

The paradox is the fact, however, that the respondents ignored the major role of trees in regulating the climate and the local environment, especially with regard to air purification and atmospheric carbon sequestration. This habit would reflect a low awareness of the inhabitants of the city of Kinshasa regarding the causes and effects of climate change, especially in urban and peri-urban areas, as well as the role of trees in mitigating these effects.

In addition, the lack of a policy and strategy to encourage urban and peri-urban forestry has been noted, resulting in the problem of the origin of the seedlings used for planting trees in the plots in this study. In fact, almost all of the trees planted in the plots were born from seeds of the fruits consumed. This reinforces the conclusions of Buisseres et al [5], which show that urban and peri-urban trees do not come from natural regeneration, unlike those growing in woodlands. Furthermore, the mission of ensuring the production, extension and planting of trees throughout the city of Kinshasa, and in the interior of the country, is the responsibility of the Ministry of the Environment and Sustainable Development. However, the reforestation services of this ministry, which were formerly in all the communes of Kinshasa, have almost disappeared or have become non-operational, due to the lack of substantial resources (financial, material and human). The public spaces formerly reserved for the large-scale production of seedlings have all been subdivided, and the few existing forest nurseries are the result of private or individual initiatives. The cost of purchasing seedlings, 1 USD/plant, remains exorbitant for residents. Current initiatives to reduce deforestation and forest degradation should guarantee the inhabitants of Kinshasa easy access to seeds and tree seedlings.

It should also be noted that, even if the residents recognized the different roles of the tree, most of them were not willing to add more trees to the plots they live in. There are several reasons for this, including lack of space, tenant status and the risk of accidents. Thus, with the strong demographic growth that the city of Kinshasa is experiencing $[3,15]$, this situation is worrisome because more and more trees are being cut down in the plots without being replaced, leaving room for buildings. This observation is supported by Buisseres et al [5], who state that in the city, trees and city dwellers are in competition for the use of space, and that the soil as a growth medium is not very available because the urban space above and below ground is furnished by several types of structures and infrastructures. This leaves very little room for tree planting. In this regard, it is relevant to establish an adequate policy of peri-urban and urban forestry to promote the planting and management of trees in the plots, as well as in green spaces. This program should include tree maintenance techniques to help residents deal with potential risks and/or accidents related to falling trees. Alongside this, in addition to awareness rising, individual reforestation actions could greatly contribute to the promotion of plot tree planting.

\section{Conclusion}

This case study highlighted the relevance and urgency of developing urban and peri-urban forestry in the provincial city of Kinshasa where the landscape is increasingly degraded due to uncontrolled urbanization. The management and development of trees and green spaces require special attention within the framework of the government program at both the central and provincial levels. Actions to be considered should include raising awareness of the role and importance of trees, promoting reforestation and tree planting in municipal spaces, including along the main arteries of cities. However, due to the complex cosmopolitan character and heterogeneity of the city of Kinshasa, it is necessary to consider continuing this study in the other communes in order to refine the knowledge of the population's perception of the role of trees in urban and peri-urban areas. This information will be useful for consolidating the actions to be recommended in the context of the development of national and provincial urban and peri-urban forestry policy.

\section{Acknowledgements}

The authors sincerely thank the authorities of the Kinkole neighborhood for their support in the realization of this study. In particular, our gratitude goes to the residents of the Kinkole neighborhood who, despite their concerns, agreed to participate freely to this survey. 


\section{References}

[1] Barima, Y. S. S., Egnankou, M. W., N'doumé, C. T. A., Kouamé, F. N. et Bogaert, J. 2010. Modeling forest landscape dynamics in the forest-savanna transition region of eastern Ivory Coast. Remote Sensing 9, 2, 129-138.

[2] Batel, L. 2015. The challenge of cities in Africa: Towards accelerated urbanization in Africa.

[3] Bogaert, J. et Halleux, J-M. 2015. Peri-urban territories: Development, issues and perspectives in the South. Gembloux Agronomic Press.

[4] Bogaert, J., Biloso M. A., Vranken I. et André, M. 2015. Periurban dynamics: landscape ecology perspectives. In Bogaert, J. et Halleux, J-M. 2015 (eds) Peri-urban territories: Development, issues and perspectives in the South. Gembloux Agronomic Press, pp 63-73.

[5] Bussières, G., Brochu, P., Coupal, M.-J., Fradette, F., Francoeur, P., Larivière, J., Paquet B., Rey-Lescure, É., Robert, M.-C., Rocray, P.-É. et Sommeillier C. 2009. "Urban forestry" in the order of forest engineers of Quebec, Manual of forestry, 2nd ed. Collective work, multi-world editions, Quebec, pp. 721-769.

[6] Delpeteau, F., 2000. The process of research in the human sciences: from the initial question to the communication of results. University of Montreal and Deboeck Press.

[7] FAO. 2012. Study on urban and peri-urban forestry in N'Djaména, Tchad. Role and Chad. Urban and Peri-Urban Forestry Working Paper No. 6. 95 pages. Rome.

[8] Kabanyegeye, H. 2021. Thirty-three years of spatial dynamics of land use in the city of Bujumbura, Republic of Burundi. Africa Science: International Journal of Science and Technology, 18, 1, 203-2015.

[9] Kabeya, M., Landu, L., Kizika, K. et Paulus J. 1994, Inventory of the domestic flora of residential plots. Case of Kinshasa (Zaire). Journal Med. Pharm. Afr., 8, 1, 55-68.

[10] Kabinda, N. L., Kaba, K. K., Nsampolu, B., Mukadi, B., Mutombo, K., Yenyi, O., Kalampayi, L. Nzangi, B., Kabumbu, M. B., De Herdt, V., Kabinda, N., Keta, C., MoritzBonnechère, P., Ngoy, L. M., Nerincx, M., Turlot, J. M. et van Boxstael. 2003. Larcier codes, Democratic Republic of Congo. Volume I: Civil and judicial law. 2003. De Boeck \& Larcier, Brussels.

[11] Kadiata, D. K. et Ndamiyehe, N. J. B. 2017. Richness of forest stands and atmospheric carbon dioxide storage in urban institutional lands of Bukavu, D. R. Congo. Journal of Forest and Environmental Science, 33, 2, 79-90.

[12] Katalayi, M. H. 2014. Urbanization and urban fabric in Kinshasa: challenges and opportunities for development. Geography. Michel de Montaigne Bordeaux III University, doctoral thesis.

[13] Kayembe, Wa Kayembe M., De Maeyer M. et Wolff E. 2009. Mapping of urban growth in Kinshasa (DR. Congo) between 1995 and 2005 by high resolution satellite remote sensing", Belgeo, 3-4.

[14] Larouche J. 2016. Urban forestry: world census of publications, current situation and research needs of Canadian municipalities. Master's thesis in forest sciences. Laval University, Canada.

[15] Lelo, N. F. 2008. City and environment. Harmattan edition, Paris.

[16] Lelo, N., F. 2018. The slums of Kinshasa (new color version). Harmattan edition, Paris.

[17] Leyden, K. M. 2003. Social Capital and the Built Environment: The Importance of Walkable Neighborhoods. American Journal of Public Health, 93 (9): 1546-1551.

[18] Makumbelo, E., Paulus, J. J., Luyindula, N., Lukoki, L. 2005. The slums of Kinshasa (new color version). Harmattan edition, Paris. Tropicultura, 23, 4, 245-252.

[19] Ncutirakiza, N. J-B et Kadiata B. D. 2017. Role, presence and need of trees in the urban landscape of Kinshasa. Annals of UNIGOMA, vii, 2, 87-102.

[20] Ogalala, Y. G. 2013. The practice of urbanization in SubSaharan Africa: Assessment and strategic perspective. The example of the city of Bangui (Central African Republic). Doctoral thesis. François-Rabelais University of Tours.

[21] Pauwels, L. and Nzayilu N'ti. 1993. Guide to trees and shrubs in the Kinshasa - Brazzaville region. Volume 4. National Botanical Garden of Belgium and Commission of European Communities. Scripta Botanica Belgica Brussels.

[22] Pauwels, L. 1982. Vascular plants around Kinshasa. Ed. Luc Pauwels, 14, av. G. Vandersmissen, 1040 Brussels.

[23] Polorigni, B., Radji R., Kokou K. 2014. Perceptions, trends and preferences in urban forestry: Case of the city of Lome in Togo . Europen Scientific Journal, 10, 5, 261-277.

[24] Radji, A., Kokou K., et Akpagana K. 2010. Woody plant species used in urban forestry in West Africa: Case study in Lomé, capital town of Togo. Journal of Horticulture and Forestry, 3, 1, 21-31.

[25] Rosen, M. 2016. Benefits, issues and challenges. Canadian Forest Service, Laurentian Forestry Center.

[26] Sambieni, K. R., Biloso, M. A., Toyi, S. M. Occhiuto, R., Bogaert, J. et Dossou, B. 2018a. Domestic tree vegetation in the urban and peri-urban landscape of the city of Kinshasa, DRC. Africa Science, 14, 2, 197-208.

[27] Sambieni, K. R., Messina, N. J. P., Biloso, M. A., Halleux, J. M., Occhiuto, R. et Bogaert, J. 2018b. The morphological urbanization status of the municipalities of Kinshasa in the DRC. Tropicultura, 36, 3, 520-530.

[28] Sambieni, K. R., Useni, S. Y., Cabala, K. S., Biloso, M. A., Munyemba, K. F., Lelo, N. F., Occhiuto, R. and Bogaert, J. 2018c. Green spaces in urban and peri-urban areas of Kinshasa in the DRC. Tropicultura, 36, 3, 478-491.

[29] Sankiana, M. G. 2012. Perspective of participatory management of protected areas in the DRC: Case of the Lomako-Yokokala Wildlife Reserve. DESS thesis, ERAIFT. Kinshasa.

[30] Simza, D. 2012. Urban forestry and its contribution to carbon sequestration: case of the city of Lomé (Togo). DEA thesis in developmental biology, University of Lome. 
[31] Tréfon, T. et Kabuyaya, N. 2015. Peri-urban spaces in Central Africa. In Bogaert, J. and Halleux, J-M. 2015 (eds.) Peri-urban territories: Development, challenges and perspectives in developing countries. The Agronomic Presses of Gembloux, pp 33-42.

[32] Useni, S. Y., Cabala, K. S., Halleux, M. J., Bogaert, J. et Munyemba, K. F. 2018. Characterization of the urban spatial growth of the city of Lubumbashi (Haut-Katanga, DRCongo) between 1989 and 2014. Tropicultura, 36, 1, 99-108.
[33] Vergiette, Y. and M. Labrecque. 2007. Roles of trees and climbing plants in an urban environment: review of the literature and attempt to extrapolate to the Montreal context: Institute for Research in Plant Biology - Montreal Botanical Garden, University of Montreal Canada.

[34] WU, J. C. HE, G. HUANG and D. YU. 2013. Urban Landscape Ecology: Past, Present, and Future pp in "Landscape Ecology for Sustainable Environment and Culture", Fu B., Jones K. B. (eds.), Springer Science + Business Media Dordrecht, 37-53. 